\title{
Breast cancer awareness and barriers to symptomatic presentation among women from different ethnic groups in
}

\section{East London}

\author{
LJL Forbes*,', L Atkins', A Thurnham', J Layburn'², F Haste ${ }^{2}$ and AJ Ramirez' \\ 'Promoting Early Presentation Group, Department of Psychological Medicine, Kings College London, South Wing, St Thomas' Hospital, London SEI 7EH, \\ UK; ${ }^{2}$ North East London Cancer Network, The Royal London Hospital, Whitechapel Road, Whitechapel, London EI IBB, UK
}

BACKGROUND: During 200 I to 2005, I-year breast cancer survival was low in ethnically diverse East London. We hypothesised that this was due to low breast cancer awareness and barriers to symptomatic presentation, leading to late stage at diagnosis in women from ethnic minorities. We examined ethnic differences in breast cancer awareness and barriers to symptomatic presentation in East London.

METHODS: We carried out a population-based survey of 1515 women aged $30+$ using the Cancer Research UK Breast Cancer Awareness Measure. We analysed the data using logistic regression adjusting for age group and level of deprivation.

RESULTS: South Asian and black women had lower breast cancer awareness than white women. South Asian women, but not black women, reported more emotional barriers to seeking medical help than white women. White women were more likely than non-white women to report worry about wasting the doctor's time as a barrier to symptomatic presentation.

CONCLUSION: Interventions to promote early presentation of breast cancer for South Asian and black women should promote knowledge of symptoms and skills to detect changes, and tackle emotional barriers to symptomatic presentation and for white women tackle the idea that going to the doctor to discuss a breast symptom will waste the doctor's time.

British Journal of Cancer (201 I) I 05, 1474-1479. doi:I0.1038/bjc.201 I.406 www.bjcancer.com

Published online II October 20। I

(c) 20II Cancer Research UK

Keywords: breast cancer; awareness; symptoms; delayed presentation; cross-sectional study; ethnic group

In women diagnosed with breast cancer in East London during 2001 to 2005, 1-year relative survival was $92 \%$ : the lowest of the 38 geographical areas covered by NHS cancer networks in England (National Cancer Intelligence Network, 2009).

One-year relative survival is an indicator of advanced stage at diagnosis; people who survive less than 1 year after diagnosis are very likely to have had the advanced disease at the time of diagnosis. The findings in East London were consistent with this: nearly $12 \%$ of women diagnosed with breast cancer in East London had stage 4 disease at diagnosis, compared with $7 \%$ in South East England as a whole (North East London Cancer Network, 2010).

Advanced stage at diagnosis may be due to delayed symptomatic presentation by patients. In breast cancer, delayed symptomatic presentation is more likely in women with non-lump symptoms and low awareness of the significance of symptoms (Ramirez et al, 1999).

Inner East London (made up of the City of London, and the London Boroughs of Hackney, Tower Hamlets and Newham) has one of the highest levels of deprivation in England. In all, $46 \%$ of residents belong to minority ethnic groups, particularly South Asian (Greater London Authority (GLA) estimates 2009).

*Correspondence: Dr LJL Forbes; E-mail: lindsay.forbes@kcl.ac.uk Received 26 May 2011; revised 9 September 2011; accepted 13 September 201 I; published online II October 201।
Asian and black women with breast cancer living in South East England are more likely to be diagnosed with metastatic disease than white women (Jack et al, 2009). One study has shown that women from UK minority ethnic groups have lower breast cancer awareness than women in the general population (Scanlon and Wood, 2005). A population-based survey of general cancer awareness in adults found that people from ethnic minority groups had lower cancer symptom awareness than white people but no evidence that they experienced more barriers to seeking medical help with symptoms that might be serious (Robb et al, 2009). However, the number of people from minority ethnic groups taking part in this survey was small (144 people, $7 \%$ of the study sample).

We hypothesised that women belonging to minority ethnic groups in East London would have low breast cancer awareness and would report greater barriers to symptomatic presentation. We carried out a survey of breast cancer awareness and barriers to symptomatic presentation in women in inner East London, focusing particularly on ethnic differences, to inform interventions to promote early presentation with breast cancer symptoms.

\section{METHODS}

We carried out a face-to-face interview survey of breast cancer awareness and barriers to symptomatic presentation in women 
aged 30 and older in the City of London and the London Boroughs of Hackney, Tower Hamlets and Newham using the Cancer Research UK Breast Cancer Awareness Measure (Linsell et al, 2010).

\section{The Cancer Research UK Breast Cancer Awareness Measure}

The Cancer Research UK Breast Cancer Awareness Measure is a validated measure of breast cancer awareness (Linsell et al, 2010). It includes questions on knowledge of symptoms of breast cancer, age-related risk of breast cancer, and the NHS Breast Screening Programme, confidence to notice a breast change, anticipated delay in presentation and frequency of breast checking. It also measures barriers to seeking medical help with symptoms that might be serious. We also asked questions about age, country of birth, ethnic group, main language spoken at home, age at leaving full-time education, main source of household income and housing tenure.

\section{Sampling}

We aimed to survey a population-representative sample of women aged 30 and older. We selected 2077 addresses from the Postal Address File from which we selected the sample.

In the first instance, we stratified lower layer super output areas (LSOAs; average population 1500) into tertiles of average deprivation (Office for National Statistics, 2011) as defined by Index of Multiple Deprivation 2007 (IMD) (Social Disadvantage Research Centre, 2008). We systematically selected 30 LSOAs, 10 from each stratum, to ensure a mix of areas of different levels of deprivation. From addresses within these LSOAs, we randomly selected 1465 addresses from the Postal Address File, on average about 50 from each LSOA.

We thought that non-white and older women might be underrepresented in the study population because they may be less likely to respond (Galea and Tracy, 2007). Therefore, we attempted to boost the numbers of participants belonging to these groups. To do this, we randomly selected half the previously selected LSOAs, and randomly selected a further 612 addresses from these. When we visited these addresses, we asked only women who belonged to non-white ethnic groups or who were aged 55 and older to take part.

\section{Fieldwork}

A trained interviewer visited each selected address between November 2009 and January 2010, visiting at different times of the day, up to three times if necessary. At each responding household, the interviewer selected one woman aged 30 or older living there using a Kish grid (Kish, 1949). The interviewer invited this woman to complete the Cancer Research UK Breast Cancer Awareness Measure in a face-to-face, computer-assisted interview, arranging another appointment if the woman was not at home at the time. Most of the interviewers spoke at least one South Asian language as well as English; where possible, they conducted interviews in the respondent's preferred language.

\section{Analysis}

We assigned each woman a quintile of deprivation based on the distribution of IMD of LSOAs of inner East London. We compared the age-sex distribution of the respondents with GLA population estimates 2006 and distribution of housing tenure and country of birth with data from the Census 2001.

We carried out all the statistical analyses in Stata version 10 (Statacorp., College Station, TX, USA). We calculated weighted percentage responses to each question of the Cancer Research UK
Breast Cancer Awareness measure using the Stata svy command. This adjusts the observed percentage for the inverse of the probability of being selected, based on the proportions of women aged 30 and older of a particular age and ethnic group estimated to be resident in each local authority area, based on GLA 2006 population estimates.

We analysed knowledge of symptoms and the increasing risk of breast cancer with age, and reported breast checking as described in our previous publication (Linsell et al, 2010). We examined the associations between each element of breast cancer awareness and barriers to presentation and the ethnic group using logistic regression, adjusting for age group and quintile of deprivation. We compared black and Asian women with white women. We excluded women from other or unknown ethnic groups from this analysis.

\section{RESULTS}

\section{Response}

Of the 2077 addresses approached, 214 were ineligible, because they were not addresses of private households or because no women aged 30 or older lived at the address. In the remaining 1863 households, $1515(81 \%)$ women aged 30 or older agreed to take part and completed the questionnaire.

\section{Description of respondents}

Table 1 shows the age distribution and socioeconomic indicators of the 1515 respondents. About half were of white ethnic origin, $22 \%$ South Asian and $17 \%$ black. A total of 111 women $(7 \%)$ belonged to other or unknown ethnic groups. The age distribution of the white and South Asian groups was broadly similar. Black women were less likely to be in the youngest age group and more likely to be in the 45-64 age group. White women were more likely to have been educated to age 17 or older, more likely to own their home, less likely to be on state benefits and more likely to live in the least deprived areas compared with Asian or black women.

Of the 333 South Asian women, 113 (34\%) described themselves as Bangladeshi, 95 (29\%) Indian and 76 (23\%) Pakistani. Of the 265 black women, $134(51 \%)$ described themselves as black African and $92(34 \%)$ as black Caribbean. Overall, 68\% spoke English and $19 \%$ South Asian languages at home.

There were more women aged 45-64 in our sample than we would have expected from GLA 2006 population estimates (40vs 21\%) and fewer women aged 30-44 (48vs 62\%) and 65+ (11 vs 18\%). The ethnic distribution of the respondents was similar to GLA 2006 estimates (white: 53 vs 53\%; Asian: 22 vs 20\%; black: 18 vs $22 \%)$. The proportion born in the UK (64\%) was similar to that reported in the Census 2001. Fewer women reported that they lived in public rented housing than in the Census 2001 (24 vs 46\%); however, there have been substantial changes in the structure of the London housing market since 2001, with an increase in private rented housing and a decrease in social housing, which may explain this finding (Communities and Local Government, 2011).

\section{Knowledge of breast cancer symptoms and age-related risk}

In all, $18 \%$ of respondents recognised five or more non-lump symptoms of breast cancer. South Asian women were very much less likely to recognise five or more non-lump symptoms of breast cancer than white women and this was highly statistically significant (Table 2). Among the South Asian women, $11 \%$ of Indian women, $6 \%$ Pakistani women and $9 \%$ Bangladeshi women recognised five or more non-lump symptoms. Black women were slightly less likely to recognise five or more non-lump symptoms of breast cancer than white women. Among the black women, $17 \%$ 
Table I Characteristics of respondents

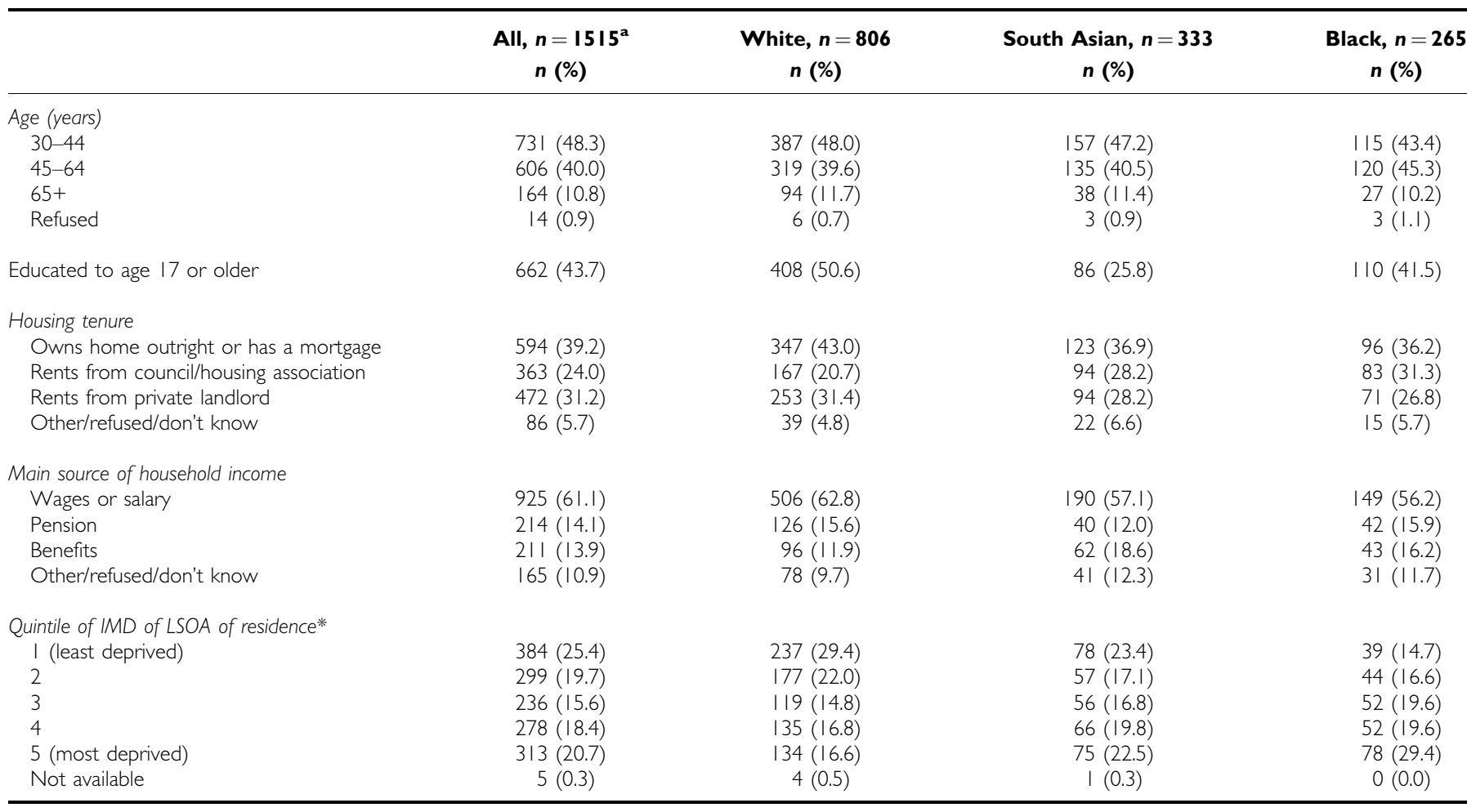

Abbreviations: IMD = index of multiple deprivation, (Department of Communities and Neighbourhoods, 2007); LSOA=lower layer super output area Census 200I. *Quintiles defined by IMD distribution of all lower super output areas in City of London, Hackney, Tower Hamlets and Newham. ${ }^{a}$ III participants were of other ethnic groups or unknown ethnic group.

Table 2 Knowledge, confidence and reported breast checking by ethnic group

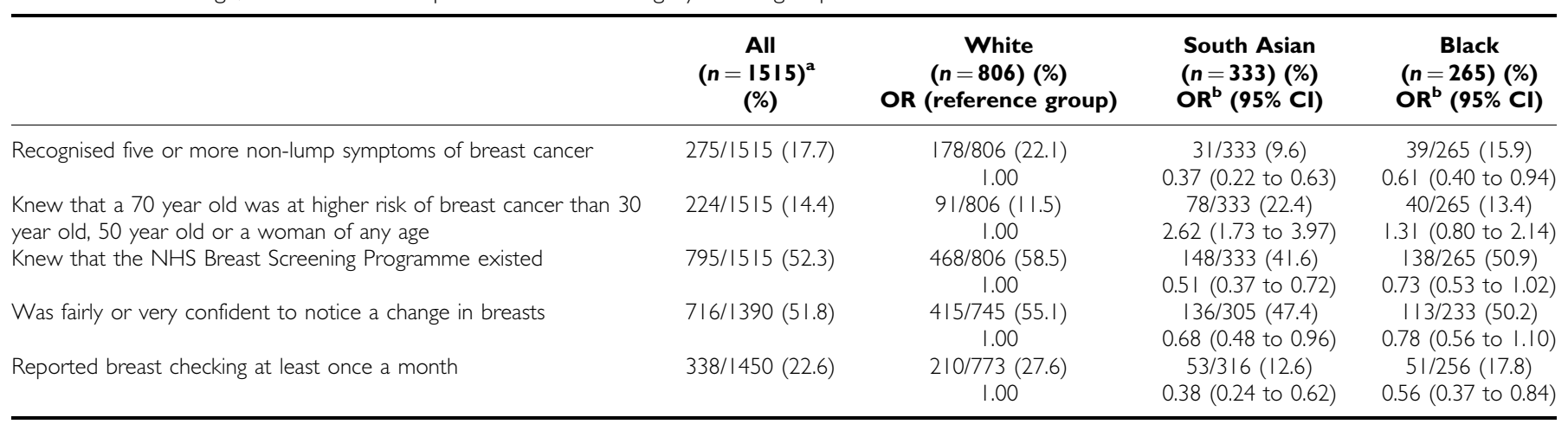

Abbreviations: $\mathrm{Cl}=$ confidence interval; $\mathrm{OR}=$ odds ratio. All percentages are weighted for inverse of the probability of being selected. ${ }^{\mathrm{a}} \mathrm{II}$ participants were of other ethnic groups or unknown ethnic group. ' Odds ratio adjusted for age group and quintile of index of multiple deprivation.

black Caribbean women and 14\% black African women recognised five or more non-lump symptoms.

In all, $14 \%$ of respondents knew that a 70 -year-old woman was at higher risk of breast cancer than a 30 -year-old woman, a 50 -year-old woman, or a woman of any age. South Asian women, but not black women, were more likely to correctly identify a 70-year-old woman was at greatest risk than white women and this was highly statistically significant (Table 2). Among South Asian women, 31\% Indian women, 18\% Pakistani women and 19\% Bangladeshi women correctly identified a 70 -year-old woman was at greatest risk.

In all, $52 \%$ of respondents reported that they knew that the NHS Breast Screening Programme existed. South Asian women, but not black women, were less likely to know of the programme than white women and this was highly statistically significant (Table 2). Among South Asian women, $46 \%$ Indian women, $51 \%$ of Pakistani women and $29 \%$ of Bangladeshi women knew of the programme.

\section{Confidence to notice breast changes, reported breast checking and anticipated delay}

In all, $52 \%$ of respondents reported that they were fairly or very confident that they would notice a change in their breasts. South Asian women, but not black women, were slightly less likely to report being confident that they would notice a change in their 
breasts than white women (Table 2). Among South Asian women, $53 \%$ Indian women, 54\% Pakistani women and $42 \%$ Bangladeshi women reported that they were confident to notice a breast change.

In all, $23 \%$ of respondents reported checking their breasts at least once a month. South Asian and black women were much less likely to report checking their breasts at least once a month than white women and this was highly statistically significant, especially for South Asian women (Table 2). Among South Asian women, $14 \%$ Indian women, 11\% Pakistani women and 9\% Bangladeshi women reported breast checking at least once a month. Among black women, $22 \%$ black Caribbean women and 15\% black African women reported breast checking at least once a month.

In all, $73 \%$ of respondents reported that they would seek medical help within 1 week of noticing a breast change and 98\% within 6 weeks. There were no significant differences in anticipated delay between the ethnic groups.

\section{Barriers to seeking medical help}

The most commonly reported barriers to seeking medical help were worry about what the doctor might find (47\%), being embarrassed to see the doctor (38\%), being worried about wasting the doctor's time $(37 \%)$ and finding it difficult to make an appointment (35\%). Table 3 shows differences by ethnic group. For some barriers, there were no differences between ethnic groups: having too many other things to worry about, being scared to see the doctor, finding the doctor difficult to talk to, finding it difficult to make an appointment and finding it difficult to arrange transport.

South Asian women were much more likely than white women to report emotional barriers: worry about what the doctor might find, embarrassment and lacking confidence talking about symptoms, and all the differences were highly statistically significant. Embarrassment was reported by $59 \%$ of Indian women, $46 \%$ of Pakistani and $66 \%$ of Bangladeshi women, worry about what the doctor might find by $46 \%$ of Indian women, $63 \%$ of Pakistani and $69 \%$ of Bangladeshi women, and not feeling confident talking about their symptom by $53 \%$ of Indian women, $49 \%$ of Pakistani and $59 \%$ of Bangladeshi women. Black women were no more likely than white women to report emotional barriers.

South Asian women were less likely than white women to report that they were too busy to make time to go to the doctor, although this was of borderline statistical significance.

White women were much more likely to report that they were worried about wasting the doctor's time than South Asian or black women and the differences were highly statistically significant.

\section{DISCUSSION}

This large population-based survey of women aged 30 and older in East London found that South Asian women's breast cancer awareness overall was low compared with white women, although their knowledge that the risk of breast cancer increases with age was greater than white women. In black women, knowledge of breast cancer symptoms and reported breast checking were low compared with white women. South Asian women, but not black women, were more likely to report emotional barriers to going to the doctor than white women. White women were more likely than South Asian and black women to report that worry about wasting the doctor's time was a barrier to going to the doctor.

Breast cancer awareness appeared low in this survey, although we have found only limited data on population levels of breast cancer awareness. A UK survey in 2005 found that $21 \%$ of women aged $18+$ agreed with the statement 'As women get older their chances of developing breast cancer increase' (Scanlon and Wood,
2005) and another in 2000 found that $30 \%$ of women aged $16+$ identified older age from a list of factors that they believed would increase the risk of breast cancer (Grunfeld et al, 2002).

Differences between ethnic groups in breast cancer awareness and barriers to symptomatic presentation were present after adjusting for age group and IMD. This suggests that the differences were not due to younger age distribution or lower socioeconomic status among non-white ethnic groups. We repeated the analyses adjusting for age at leaving full-time education but this made little difference to the results (data not shown) suggesting that lower breast cancer awareness in non-white ethnic groups was not due to lower level of education.

Among South Asian women, there was a trend to suggest that Bangladeshi women, and to a lesser extent Pakistani women, had lower breast cancer awareness than Indian women. Among black women, there was a trend to suggest that black African women had lower breast cancer awareness than black Caribbean women. We did not analyse this statistically because of small numbers.

A possible explanation of lower breast cancer awareness in non-white women is that they may perceive their risk to be lower (correctly: the incidence of breast cancer in UK South Asian and black women is lower than in white women (Jack et al, 2009)) and consequently may not absorb health promotion messages about breast cancer from charities and the NHS because they see them as irrelevant. We have found no published quantitative evidence about risk perceptions of breast cancer among non-white women living in the UK. However, a qualitative study in women from different minority ethnic groups in East London found that all considered themselves at lower risk of breast cancer than the white population (Pfeffer, 2004).

One possible explanation for the high level of emotional barriers to presentation among South Asian women is poor command of English: South Asian women are less likely to speak English well than the white population (Modood et al, 1997), and have poorer employment opportunities (Tackey et al, 2006) and, therefore, more limited opportunities to speak English. However, our finding that South Asian women did not find it more difficult to speak to their doctors provides evidence against this. Cultural differences in attitudes to using of health services may create barriers; for example, South Asian women living in Canada reported that they felt they should be accompanied by a relative if they went to the doctor, and would not want to be left alone with a doctor with a complaint of a 'private' nature (Bottorff et al, 1998).

Our findings that South Asian women had better knowledge of age-related risk of breast cancer and that South Asian and black women were less likely to check their breasts than white women are broadly consistent with a previous survey examining breast cancer awareness in different ethnic groups (Scanlon and Wood, 2005). We were surprised by South Asian women's better knowledge of age-related risk but cannot explain it.

The strengths of our study were the large sample that was representative of the target population, the large numbers of women from different ethnic groups, the very high response and the use of validated instruments (Stubbings et al, 2009; Linsell et al, 2010). The response rate was particularly high, which we think is most likely to be due to fieldworkers who spoke a variety of South Asian languages and the many attempts they made at different times of day to contact participants.

We acknowledge that we carried out multiple significance tests (30); with 30 comparisons at the $5 \%$ level of significance, two of the significant findings may be false positive. As we found thirteen statistically significant differences, of which nine were very highly statistically significant (as indicated by the values of the $95 \%$ confidence intervals), this does not alter our conclusions.

The finding that white women were more likely to report that worry about wasting the doctor's time was a barrier to seeking medical help than non-white groups is intriguing, and is consistent with a previous survey of cancer awareness in general (Robb et al, 
Table 3 Barriers to seeking medical help by ethnic group

\begin{tabular}{|c|c|c|c|c|}
\hline & All $(n=15 \mid 5)^{a}(\%)$ & $\begin{array}{l}\text { White }(n=806) \\
\text { (\%) OR (reference group) }\end{array}$ & $\begin{array}{l}\text { South Asian }(n=333) \\
(\%) \text { OR }(95 \% \mathrm{Cl})^{\mathrm{b}}\end{array}$ & $\begin{array}{l}\text { Black }(n=265) \\
(\%) \text { OR }(95 \% \mathrm{Cl})^{\mathrm{b}}\end{array}$ \\
\hline \multicolumn{5}{|l|}{ Emotional barriers } \\
\hline Too embarrassed to go and see the doctor & $543 / 1449(37.7)$ & $\begin{array}{c}222 / 784(31.3) \\
1.00\end{array}$ & $\begin{array}{c}189 / 305(61.2) \\
4.24(3.00 \text { to } 6.00)\end{array}$ & $\begin{array}{c}89 / 254(29.9) \\
1.07(0.74 \text { to } 1.54)\end{array}$ \\
\hline Lacks confidence talking about symptoms & $432 / 1450(29.0)$ & $\begin{array}{c}\text { 138/777 (18.8) } \\
1.00\end{array}$ & $\begin{array}{c}180 / 313(54.9) \\
5.40(3.77 \text { to } 7.74)\end{array}$ & $\begin{array}{c}65 / 253(23.9) \\
1.40(0.94 \text { to } 2.08)\end{array}$ \\
\hline \multicolumn{5}{|l|}{ Practical barriers } \\
\hline Too many other things to worry about & $470 / 1468(33.3)$ & $\begin{array}{c}257 / 788(36.5) \\
1.00\end{array}$ & $\begin{array}{c}101 / 315(29.6) \\
0.80(0.55 \text { to } 1.16)\end{array}$ & $\begin{array}{c}80 / 255(31.5) \\
0.87(0.61 \text { to } 1.24)\end{array}$ \\
\hline Too busy to make time to go to the doctor & $512 / 1482(33.0)$ & $\begin{array}{c}275 / 794(34.8) \\
1.00\end{array}$ & $\begin{array}{c}109 / 316(27.9) \\
0.69(0.48 \text { to } 0.98)\end{array}$ & $\begin{array}{c}88 / 261 \text { (34.0) } \\
0.98(0.69 \text { to } 1.39)\end{array}$ \\
\hline Worried about wasting the doctor's time & $519 / 1466(36.5)$ & $\begin{array}{c}368 / 786(52.7) \\
1.00\end{array}$ & $\begin{array}{c}68 / 313(16.7) \\
0.20(0.13 \text { to } 0.32)\end{array}$ & $\begin{array}{c}60 / 257(20.9) \\
0.27(0.18 \text { to } 0.40)\end{array}$ \\
\hline Finds it difficult to make an appointment & $523 / / 457(35.3)$ & $\begin{array}{c}276 / 782(36.0) \\
1.00\end{array}$ & $\begin{array}{c}133 / 316(41.0) \\
1.21(0.87 \text { to } 1.70)\end{array}$ & $\begin{array}{c}82 / 254(29.6) \\
0.74(0.52 \text { to } 1.05)\end{array}$ \\
\hline
\end{tabular}

Abbreviations: $\mathrm{OR}=$ odds ratio; $\mathrm{Cl}=$ confidence interval. All percentages are weighted for the inverse of the probability of being selected. ${ }^{\mathrm{a}} \mathrm{I}$ I participants were of other ethnic groups or unknown ethnic group. ' ${ }^{b}$ dds ratio adjusted for age group and quintile of index of multiple deprivation.

2009). International differences in cancer awareness and beliefs (including worry about wasting the doctor's time) may contribute to international differences in 1-year relative survival (Coleman et al, 2010), a hypothesis currently being explored by the International Cancer Benchmarking Partnership (http://info. cancerresearchuk.org/spotcancerearly/ICBP/).

There is a growing body of evidence suggesting that low breast cancer awareness is associated with poorer survival in breast cancer through the mechanism of delayed presentation. Low breast cancer awareness is a risk factor for delayed presentation in breast cancer (Ramirez et al, 1999). There is strong evidence that delay in diagnosis is associated with poorer survival in breast cancer (Richards et al, 1999) and that late diagnosis is a major factor accounting for breast cancer survival differences between rich and poor women (Downing et al, 2007), black and white women (Jack et al, 2009), and UK and other European countries (Sant et al, 2003). Our findings suggest that low breast cancer awareness may contribute to later stage at diagnosis observed in South Asian and black women living in the UK (Jack et al, 2009).

Our findings provide evidence that interventions to promote early presentation in breast cancer should be tailored for women from different ethnic groups. In particular, interventions for South Asian women should focus on promoting knowledge of breast cancer symptoms and the NHS Breast Screening Programme, promoting confidence and skills to detect breast changes and tackling emotional barriers to attending the doctor. Interventions for black women should focus on promoting knowledge of breast cancer symptoms and skills to detect breast changes and for white women on tackling the idea that going to the doctor to discuss a breast symptom will waste the doctor's time.

We have developed and evaluated an intervention to provide women with the knowledge, confidence, motivation and skills to present promptly with breast cancer symptoms (the Promoting Early Presentation Intervention; Forbes et al, 2011), which is currently being piloted within the NHS Breast Screening Programme. We are now planning to identify settings in which to promote early presentation and models of delivery to reach women in ethnic minority groups who may not attend breast screening.

\section{ACKNOWLEDGEMENTS}

We acknowledge Ethnic Focus Research and Intelligence for carrying out the fieldwork. The English Department of Health, for funding the study and Breast Cancer Care and Breakthrough Breast Cancer, which funded the validation of the Cancer Research UK Cancer Awareness Measure.

\section{REFERENCES}

Bottorff JL, Johnson JL, Bhagat R, Grewal S, Balneaves LG, Clarke H, Hilton BA (1998) Beliefs related to breast health practices: the perceptions of South Asian women living in Canada. Social Sci Med 47: 2075-2085

Coleman M, Forman D, Bryant H, Butler J, Rachet B, Maringe C, Nur U, Tracey E, Coory M, Hatcher J, McGahan C, Turner D, Marrett L, Gjerstorff $M$, Johannesen $T$, Adolfsson J, Lambe M, Lawrence $G$, Meechan D, Morris E, Middleton R, Steward J, Richards M, The ICBP

Module Working Group (2010) Cancer survival in Australia, Canada, Denmark, Norway, Sweden, and the UK, 1995-2007 (the International Cancer Benchmarking Partnership): an analysis of population-based cancer registry data. Lancet 377: $127-138$

Communities and Local Government (2011) Live tables on housing stock. http://www.communities.gov.uk/housing/housingresearch/housingstatistics/ housingstatisticsby/stockincludingvacants/livetables/. Accessed 6 September 2011 
Downing A, Prakash K, Gilthorpe MS, Stefoski MJ, Forman D (2007) The effect of socioeconomic background on stage at diagnosis, treatment pattern and survival in women with invasive breast cancer. Br J Cancer 96: 836-840

Forbes LJL, Linsell L, Atkins L, Burgess C, Tucker L, Omar L, Ramirez AJ (2011) A promoting early presentation intervention increases breast cancer awareness in older women after 2 years: a randomised controlled trial. $B r$ J Cancer 105: $18-21$

Galea S, Tracy M (2007) Participation rates in epidemiologic studies. Ann Epidemiol 17: $643-653$

Grunfeld EA, Ramirez AJ, Hunter MS, Richards MA (2002) Women's knowledge and beliefs regarding breast cancer. Br J Cancer 86: 1373 - 1378

Jack RH, Davies EA, Moller H (2009) Breast cancer incidence, stage, treatment and survival in ethnic groups in South East England. $\mathrm{Br} J$ Cancer 100: $545-550$

Kish L (1949) A procedure for objective respondent selection within the household. J Am Stat Assoc 44: 380-387

Linsell L, Forbes LJ, Burgess C, Kapari M, Thurnham A, Ramirez AJ (2010) Validation of a measurement tool to assess awareness of breast cancer. Eur J Cancer 46: $1374-1381$

Modood T, Berthoud R, Lakey J, Nazroo J, Smith P, Virdee S, Beishon S (1997) Diversity and Disadvantage: Fourth National Survey of Ethnic Minorities. Policy Studies Institute: London

National Cancer Intelligence Network (2009) One Year Cancer Survival by Cancer Network, England, 2001-2004. National Cancer Intelligence Network: London

North East London Cancer Network (2010) Breast Cancer Inequalities Project. http://www.towerhamlets.nhs.uk/about-us/public-health/our-priorities/ cancer/research-into-public-awareness-of-cancer/. Accessed 1 February 2010

Office for National Statistics (2011) Superoutput Areas: Introduction. http://www.neighbourhood.statistics.gov.uk/dissemination/Info.do?page = aboutneighbourhood/geography/superoutputareas/soa-intro.htm. Accessed 6 June 2011

Pfeffer N (2004) Screening for breast cancer: candidacy and compliance. Soc Sci Med 58: $151-160$
Ramirez AJ, Westcombe AM, Burgess CC, Sutton S, Littlejohns P, Richards MA (1999) Factors predicting delayed presentation of symptomatic breast cancer: a systematic review. Lancet 353: $1127-1131$

Richards MA, Westcombe AM, Love SB, Littlejohns P, Ramirez AJ (1999) Influence of delay on survival in patients with breast cancer: a systematic review. Lancet 353: $1119-1126$

Robb KA, Stubbings S, Ramirez A, Macleod U, Austoker J, Waller J, Hiom S, Wardle J (2009) Public awareness of cancer in Britain. $\mathrm{Br} J$ Cancer 101: s18-s23

Sant M, Allemani C, Capocaccia R, Hakulinen T, Aareleid T, Coebergh JW, Coleman MP, Grosclaude P, Martinez C, Bell J, Youngson J, Berrino F, EUROCARE Working Group (2003) Stage at diagnosis is a key explanation of differences in breast cancer survival across Europe. Int $J$ Cancer 106: $416-422$

Scanlon K, Wood A (2005) Breast cancer awareness in Britain: are there difference based on ethnicity? Divers Health Soc Care 2: 211-221

Social Disadvantage Research Centre (2008) In: Noble M, McLennan D, Wilkinson K, Whitworth A, Barnes H, Dibben C (eds). The English Indices of Deprivation 2007. Communities and Local Government: London

Stubbings S, Robb J, Macleod U, Hiom S, Wardle J (2009) Development of a measurement tool to assess public awareness of cancer. Br J Cancer 101: s13-s17

Tackey ND, Casebourne J, Aston J, Ritchie H, Sinclair A, Tyers C, Hurstfield J, Willison R, Page R (2006) Barriers to Employment for Pakistanis and Bangladeshis in Britain. Research Report DWPRR 36. Department for Work and Pensions: London

(c) (D) This work is licensed under the Creative Commons (C) NC SA Attribution-NonCommercial-Share Alike 3.0 Unported License. To view a copy of this license, visit http://creativecommons.org/ licenses/by-nc-sa/3.0/ 